\title{
Traditional Antiepileptics Remain First Line Treatment for Children with Epilepsy at The University Hospital of the West Indies, Kingston, Jamaica \\ N Morrison-Levy, R Melbourne-Chambers
}

\begin{abstract}
Objectives: To describe the demography of epilepsy in children at the University Hospital of the West Indies and to review the frequency of major seizure types and antiepileptic drug therapy used at diagnosis.

Methods: The records of all children ages two months to 12 years with two or more unprovoked seizures, on at least two separate days between January 2001 and December 2005 at the paediatric in-patient unit and paediatric neurology clinic were reviewed. Descriptive analyses (Chi-squared tests) were performed utilizing the Statistical Programme for Social Sciences (SPSS version 14). Statistical significance, $\mathrm{p}<0.05$.

Results: Sixty-three children were enrolled in the study; thirty-two (50.8\%) were males. The median (minimum, maximum) age was $35(2,144)$ months at seizure onset. $\mathrm{N}(65 \%)$ had focal seizures of which dyscognitive seizures were the most frequent subtype. Generalized tonic clonic and myoclonic seizures were the most frequent of the generalized seizures. Nineteen $(30 \%)$ children had more than one seizure type and $17(27 \%)$ of the children were diagnosed with an epilepsy syndrome. West syndrome was the commonest of the epilepsy syndromes. Carbamazepine was the most frequently prescribed drug at initial diagnosis for focal seizures. Valproic acid was the drug of choice for generalized seizures.

Conclusion: There was no sex predilection in epilepsy in this population. Focal seizures were commonest and Carbamazepine was the choice drug for focal seizures and Valproic acid for generalized seizures.
\end{abstract}

Keywords: Epilepsy, focal seizures, generalized seizures, seizures

From: Department of Child and Adolescent Health, University of the West Indies (UWI), Mona, Jamaica

Correspondence: Dr Nadine Morrison- Levy, Department of Child and Adolescent Health, University Hospital of the West Indies (UWI), Mona, Jamaica. Phone \# (876) - 853 - 1593, E-mail: nadinelevy.morrison74@gmail.com or nadine.morrisonlevy@uwimona.edu.jm 


\section{INTRODUCTION}

Epilepsy is one of the more common brain disorders in childhood (1). The prevalence of epilepsy in childhood is reported to be higher in developing countries (1). In Jamaica, the prevalence of epilepsy was reported as 5.8 per 1000 in 2-9 year-old children (2) which is closer to the prevalence in the United States of America (USA) of 6.3 per 1000 children (3) and Japan 5.3 to 8.8 per 1000 (4). The most common seizure types seen in paediatric epilepsy vary. In Turkey, the most common seizure types in the age group 0 to 18 years were generalized tonic-clonic seizures and focal seizures with secondary generalizations (5) whilst in Cuba and the USA in children younger than 15 years, focal and generalized seizures were the most frequently seen $(6,7)$.

Antiepileptic drug prescribing patterns also vary. In the developing nations of Africa, Carbamazepine and Phenobarbitone are the most frequently prescribed first line drugs (8). This was similar to Canada (9), whilst in three European countries Valproic acid and Carbamazepine were frequently prescribed (10). The distribution of seizure types amongst children in the Jamaican population is not known nor has antiepileptic drug prescribing pattern been documented. This study aimed to describe the demography of epilepsy in childhood at the University Hospital of the West Indies and to review the frequency of the major seizure types and antiepileptic drug therapy at diagnosis.

\section{METHODS}

This was a retrospective study of children aged two months to 12 years with epilepsy managed at the University Hospital of the West Indies between January 1, 2001 and December 31, 2005. The University Hospital of the West Indies is a tertiary level hospital located in Kingston, the capital of Jamaica and accepts referrals from medical facilities island-wide. At the time of the 
study, only children age 12 years and younger were being registered as new patients in the Paediatric Department. A case was defined as a child age two months to 12 years with two or more unprovoked seizures on at least two separate days managed and followed-up at the University Hospital of the West Indies. Children with provoked seizures, febrile seizures and seizures on-going from the neonatal period were excluded. The records of all children ages two months to 12 years presenting with two or more unprovoked seizures on at least two separate days between January 2001 and December 2005 at the paediatric neurology clinic and paediatric in-patient unit of the University Hospital of the West Indies were reviewed. These children were identified by reviewing the admission registers in the paediatric medical wards and the paediatric neurology clinic registration log book using the search terms - fits, seizure, seizure disorder, convulsions and epilepsy. From this patient population, study cases fulfilling the case definition were selected. The diagnoses were confirmed by consultation with the paediatric neurologists. Data were extracted from the medical record and entered on to a data extraction sheet. Information on the demographics, seizures types in each patient and treatment were collected. Descriptive analyses (Chi-squared tests) were performed utilizing the Statistical Programme for Social Sciences (SPSS version 14). Statistical significance was taken at $p<0.05$. Ethical approval for the conduct of the study was obtained from The University of the West Indies/University Hospital of the West Indies Ethics Committee of the Faculty of Medical Sciences, University of the West Indies Mona. 


\section{RESULTS}

Hospital records of 63 children were reviewed; thirty-two (50.8\%) were male. The median (minimum, maximum) age of onset of seizures was $35(2,144)$ months. There was no significant sex difference in the age at onset.

\section{Seizure/ epilepsy types}

At initial presentation, 41 (65\%) patients had focal seizures (Table 1). Twenty-four (38\%) patients had dyscognitive seizures, $11(17 \%)$ patients had focal seizures evolving to bilateral convulsive seizures and six (10\%) had focal seizures without impairment of awareness (Table 1).

Table 1: Frequency of seizure types and antiepileptic drugs at initial presentation in children ages two months to 12 years with Epilepsy at University Hospital of the West Indies

\begin{tabular}{lc}
\hline Seizure types and drugs & N (\%) \\
\hline Focal seizures & $41(65)$ \\
Dyscognitive seizures & $24(38)$ \\
Focal seizures evolving to bilateral convulsive seizures & $11(17)$ \\
Focal seizures without impairment of Awareness & $6(10)$ \\
& \\
& \\
Generalized seizures & $22(35)$ \\
Myoclonic & $7(11)$ \\
Generalized tonic-clonic & $6(10)$ \\
Generalized tonic & $4(6)$ \\
Absence & $4(6)$ \\
Generalized clonic & $1(2)$
\end{tabular}

Drugs prescribed at initial presentation

Carbamazepine

Valproic acid

Phenobarbitone

Clonazepam

Prednisone
26 (41.3)

14 (22.2)

$6(9.5)$

$2(3.2)$

1 (1.6) 
Twenty-two (35\%) patients had generalized seizures. The most common types of generalized seizures were myoclonic and generalized tonic - clonic seizures in $13(21 \%)$ patients. Nineteen $(30 \%)$ patients had more than one seizure type. Eight (13\%) patients had both focal and generalized seizures (Table 2). Seven (11\%) patients with focal seizures later had generalized seizures. None of the patients with generalized seizures developed focal seizures later.

Table 2: Frequency of seizure types in two age groups and initial antiepileptic drug compared with seizure type of children with epilepsy at University Hospital of the West Indies 2001-2005

\begin{tabular}{lcccc}
\hline \multicolumn{5}{c}{ Seizure types $\mathbf{N}(\%)$} \\
\hline Partial & Generalized & Both & p-value \\
\hline Age (Months) & & & \\
$>36$ & $9(31)$ & $14(48.3)$ & $6(20.7)$ & 0.006 \\
& $24(70.6)$ & $8(23.5)$ & $2(5.9)$ & \\
Drugs & & & \\
Carbamazepine & & & \\
Valproic acid & $18(69.2)$ & $4(15.4)$ & $4(15.4)$ & 0.024 \\
& $5(35.7)$ & $9(64.2)$ & $0(0)$ & 0.021 \\
\hline
\end{tabular}

Seventeen (27\%) patients were diagnosed with an epilepsy syndrome. The commonest epilepsy syndrome identified was West syndrome which was diagnosed in $10(16 \%)$ and self-limited epilepsy with centrotemporal spikes in six (10\%). One (2\%) patient had Lennox Gastaut syndrome. West syndrome was diagnosed at a mean (sd) age of 6.5 (4.4) months. The mean (sd) age at diagnosis of children with self-limited epilepsy with centrotemporal spikes was 96 (21.5) months. The patient with Lennox Gastaut syndrome was diagnosed at age five months. Twenty-nine 
(46.0\%) children were younger than 36 months. In this age group, 14 (48.3\%) patients had generalized seizures, nine (31.0\%) had focal seizures and six (20.7\%) had both seizure types. Thirty-four (54\%) patients were 36 months of age or older. In this age group, 24 (70.6\%) had focal seizures, eight (23.5\%) had generalized seizures and two (5.9\%) had both seizure types. Generalized seizures were more frequent in children younger than 36 months old and focal seizures more frequent in children age 36 months and older $(p=0.006)$ [Table 2].

\section{Antiepileptic drug therapy}

The most frequently prescribed antiepileptic drugs at initial presentation were Carbamazepine in 26 (41.3\%) patients and Valproic acid in 14 (22.2\%) patients (Table 1). Carbamazepine was the drug most commonly prescribed for children with focal seizurs and Valproic acid for children with generalized seizures. In patients who failed to respond fully to first line therapy or in whom there were abnormal laboratory results necessitating change to a second drug, the antiepileptic drugs commonly prescribed were Topiramate, Carbamazepine, Valproic acid and Clonazepam. Thirteen (21\%) children failed to respond to the first prescribed drug and required a second drug.

\section{DISCUSSION}

This study was conducted in a tertiary referral institution in Jamaica, a middle developing country. Focal seizures were most common and occurred more frequently in children three years and older. The most common epilepsy syndromes were West Syndrome and self-limited epilepsy with Centrotemporal Spikes. Valproic acid and carbamazepine were the most commonly prescribed 
antiepileptic drugs. In this study there was no sex predilection. Similar findings have been noted in other populations of Chile (11) and USA [Connecticut] (12). However, studies from Turkey (13), Lithuania (14) and Mississippi, United States have shown a male predilection (15). Previous data from other local studies have yielded conflicting results.

In the Jamaica cohort study of sickle cell disease, the investigators found that male gender was associated with an increased risk of developing epilepsy in children with sickle cell disease (16). The median age of onset of epilepsy was 36 months which is comparable to data published by Banu and colleagues who documented a median age of three years in children with epilepsy ages two months to 15 years in Bangladesh (17). The distribution of seizure types in our population is similar to published reports of other populations. In our population, focal epilepsy was diagnosed in $65 \%$ of the patients and generalized epilepsy in 35\%. Dyscognitive seizures (previously called complex partial seizures) were the most frequent of the partial seizures whilst generalized tonic clonic and myoclonic seizures were the most frequent in those with generalized epilepsy. Sillanpaa and colleagues similarly documented that focal seizures occurred in $64 \%$ of patients in children younger than 16 years in Finland (18). Focal seizures were also the most frequent seizure type noted in other studies in rural Kenya (19), Northern Sweden (20), Singapore (21) and the United States (7). There was a low prevalence of absence epilepsy in our population. In a Swedish study of school age children, absence seizures were present in $24.5 \%$ (20). The low prevalence of absence epilepsy in our population may be due to the lack of inclusion of adolescents older than age 12 years or failure of recognition by families and teachers. There was a significant association of age with seizure type in this study. Generalized seizures were more frequent in children younger than 36 months whilst focal seizures were commonest in children 36 months and older. A similar finding has been noted by Ogunlesi et al who reviewed the records of children aged six months to 
three years managed at a paediatric neurology clinic in Nigeria. Generalized tonic - clonic seizures occurred in $55(76.9 \%)$, complex partial seizures in eight $(6.3 \%)$ and two (4.8\%) patients had BECTS (22). Kong and colleagues documented generalized seizures as the most frequent seizure type in children in China younger than five years (23). Both authors cited perinatal factors as frequent causes of epilepsy in this age group. In this study, we found that an epilepsy syndrome was documented in $27 \%$ of the children. Epidemiological studies from Japan in 2006 documented epilepsy syndromes in $15 \%$ (4) and from Sweden in $49.4 \%$ (20). In our study, amongst children ages two to 15 months, West syndrome was the commonest epilepsy syndrome; and in the age group 72-120 months, self-limited epilepsy with centrotemporal spikes was the most frequent.

In a Spanish study, West syndrome was the more frequent epilepsy syndrome in infancy and self-limited epilepsy with centrotemporal spikes in school-aged children (24). In Sweden, self-limited epilepsy with centrotemporal spike was commonest overall (20). In our study, few other epilepsy syndromes were described. This may reflect under-recognition of these types due to reduced availability of EEGs or under-representation due to the sample size. Carbamazepine was the drug of choice for treatment of children with focal seizures and valproic acid for the treatment of generalized seizures in our study. This was comparable to other international studies where conventional antiepileptic drugs are still the drugs of first choice despite the presence of newer antiepileptic agents. In a European study, conducted in 2005 which included three countries, Italy, Netherlands and the United Kingdom, valproic acid and carbamazepine were the drugs most frequently prescribed for children with epilepsy 0 to 11 years (10). Similarly, Tan et al documented in 2009 that valproic acid was the most frequently prescribed drug to treat epilepsy in children from Singapore despite the availability of newer drugs (25). Carbamazepine was noted to be the drug of choice for treatment of focal seizures and valproic acid for primary generalized 
seizures in the USA in a 2010 report (26). Epilepsy in this population of Jamaican children affects males and females equally. Focal epilepsy is the commonest subtype and infantile spasms is the most frequently recognised epilepsy syndrome. Carbamazepine and valproic acid are the preferred drugs for children with epilepsy at initial diagnosis. This study was retrospective and data were missing for a few variables. Despite this, we found that epilepsy in childhood in Jamaica at the University Hospital of the West Indies is similar in seizure types and the epilepsy syndromes represented to reports from other countries. The pattern of antiepileptic drug therapy is similar to that in developing countries.

\section{ACKNOWLEDGEMENT}

We would wish to thank David Levy for technical assistance and the medical records department at the University Hospital of the West Indies who made the patients records available for data extraction.

\section{Conflict of interest}

We wish to confirm that there are no known conflict of interest as it relates to the publication of this paper, there was no financial support for this work that would influence its outcome. 


\section{REFERENCES}

1. Engel J, Birbeck GR, Diop AM, Jain S, Palmini A. Epilepsy: Global Issues for the practicing Neurologist. New York, USA: Demos Medical Publishers; 2005.

2. Durkin MS, Davidson LL, Hasan ZM, Hasan Z, Hauser WA, Khan N, et al. Estimates of the prevalence of childhood seizure disorders in communities where professional resources are scarce: results from Bangladesh, Jamaica and Pakistan. Paediatr Perinat Epidemiol J 1992; 6: 166-80.

3. Russ SA, Larson K, Halfon N. A national profile of childhood epilepsy and seizure disorder. Pediatrics J 2012; 129: 256-64.

4. Oka E, Ohtsuka Y, Yoshinaga H, Murakami N, Kobayashi K, Ogino T. Prevalence of childhood epilepsy and distribution of epileptic syndromes: a population-based survey in Okayama, Japan. Epilepsia J 2006; 47: 626-30.

5. Arhan E, Serdaroglu A, Kurt AN, Aslanyavrusu M. Drug treatment failures and effectivity in children with newly diagnosed epilepsy. Seizure J 2010; 19: 553-7.

6. Nicholas Garofalo Gomez AMGG, Otaman Fernandez Concepcion, Carol S. Camfield, Peter R. Camfield. Prevalence, syndromes and severity of childhood epilepsy in Cuba. Journal of Pediatric Neurology 2012; 10: 23-8.

7. Berg AT, Shinnar S, Levy SR, Testa FM. Newly diagnosed epilepsy in children: presentation at diagnosis. Epilepsia J 1999; 40: 445-52.

8. Osemeke NP AA, Obunike AE, Okechukwu EK, Cosmas NM, Adesola O. Patterns of Antiepileptic Drug Use and Seizure Control Among People With Epilepsy In A Suburban Community In Southeast Nigeria. African Journal of Neurological Sciences 2012; 31: 3642

9. Camfield PR, Camfield CS, Gordon K, Dooley JM. If a first antiepileptic drug fails to control a child's epilepsy, what are the chances of success with the next drug? J Pediatr 1997; 131: 821-4.

10. Hsia Y, Neubert A, Sturkenboom MC, Murray ML, Verhamme KM, Sen F, et al. Comparison of antiepileptic drug prescribing in children in three European countries. Epilepsia J 2009; 51: 789-96.

11. Lavados J, Germain L, Morales A, Campero M, Lavados P. A descriptive study of epilepsy in the district of El Salvador, Chile, 1984-1988. Acta Neurol Scand J 1992; 85: 249-56.

12. Shamansky SL, Glaser GH. Socioeconomic characteristics of childhood seizure disorders in the New Haven area: an epidemiologic study. Epilepsia J 1979; 20: 457-74. 
13. Serdaroglu A, Ozkan S, Aydin K, Gucuyener K, Tezcan S, Aycan S. Prevalence of epilepsy in Turkish children between the ages of 0 and 16 years. J Child Neurol 2004; 19: 271-4.

14. Endziniene M, Pauza V, Miseviciene I. Prevalence of childhood epilepsy in Kaunas, Lithuania. Brain Dev 1997; 19: 379-87.

15. Haerer AF, Anderson DW, Schoenberg BS. Prevalence and clinical features of epilepsy in a biracial United States population. Epilepsia J 1986; 27: 66-75.

16. Ali SB, Reid M, Fraser R, MooSang M, Ali A. Seizures in the Jamaica cohort study of sickle cell disease. Br J Haematol 2010; 151: 265-72.

17. Banu SH, Khan NZ, Hossain M, Jahan A, Parveen M, Rahman N, et al. Profile of childhood epilepsy in Bangladesh. Dev Med Child Neurol J 2003; 45: 477-82.

18. Sillanpaa M, Jalava M, Shinnar S. Epilepsy syndromes in patients with childhood-onset seizures in Finland. Pediatr Neurol J 1999; 21: 533-7.

19. Munyoki G, Edwards T, White S, Kwasa T, Chengo E, Kokwaro G, et al. Clinical and neurophysiologic features of active convulsive epilepsy in rural Kenya: a population-based study. Epilepsia 2010; 51: 2370-6.

20. Larsson K, Eeg-Olofsson O. A population based study of epilepsy in children from a Swedish county. Eur J Paediatr Neurol 2006; 10: 107-13.

21. Chan D, Phuah HK, Ng YL, Choong CT, Lim KW, Goh WH. Pediatric epilepsy and first afebrile seizure in Singapore: epidemiology and investigation yield at presentation. J Child Neurol 2010; 25: 1216-22.

22. Ogunlesi T, Ogundeyi M, Olowu A. Pattern of childhood epilepsies in Sagumu, Nigeria. Indian J Pediatr 2009; 76: 385-9.

23. Kwong KL, Chak WK, Wong SN, So KT. Epidemiology of childhood epilepsy in a cohort of 309 Chinese children. Pediatr Neurol J 2001; 24: 276-82.

24. Dura-Trave T, Yoldi-Petri ME, Gallinas-Victoriano F. Epilepsy in children in Navarre, Spain: epileptic seizure types and epileptic syndromes. J Child Neurol 2007; 22: 823-8.

25. Tan WW, Kong ST, Chan DW, Ho PC. A retrospective study on the usage of antiepileptic drugs in Asian children from 2000 to 2009 in the largest pediatric hospital in Singapore. Pharmacoepidemiol Drug Saf 2012; 21: 1074-80.

26. Goldenberg MM. Overview of Drugs Used for Epilepsy and Seizures. Etiology, Diagnosis and Treatment. Pharmacy and Therapeutics J 2010; 35: 392-415. 